\title{
Projeto Colmeia: Elaboração de Site Educacional como Ferramenta para Gamificação
}

\author{
Vinícius M. S. Santos1, Maria E. A. Carvalho1, Ricardo P. Silva1, Paulo A. Silva1 \\ 1 Licenciatura em Ciências Biológicas, Universidade Federal de Pernambuco, Centro \\ Acadêmico de Vitória (UFPE-CAV) \\ vinicius.matheus86@hotmail.com, \{carvalhomeac100, ricardo.pedrope, \\ profe.pas\}@gmail.com
}

\begin{abstract}
This paper aims to report on the construction of a website for the Colmeia Game extension project, as an auxiliary element in the process of gamification of the Didactics and Learning Assessment disciplines. Aims to promote the better experience of students involved in the project. The website was built using the unified WIX SITE platform that allows you to create HTML5 websites and mobile sites. The website developed was during the first semester of 2019, seeking to address a perceived problem regarding the immersion of students in the game's narrative. This website as a support tool for the gamification process. It is expected that it will allow learners greater access to information and consequent interaction.
\end{abstract}

Resumo: Este trabalho tem como objetivo relatar a construção de um site para o projeto de extensão Colmeia Game, como elemento auxiliar no processo de gamificação das disciplinas de Didática e Aprendizagem. Visa promover a melhor experiência dos alunos envolvidos no projeto. $O$ site foi criado usando a plataforma unificada WIX SITE, que permite criar sites HTML5 e sites móveis. O site foi desenvolvido durante o primeiro semestre de 2019, buscando abordar um problema percebido em relação à imersão dos alunos na narrativa do jogo. Este site é uma ferramenta de suporte para o processo de gamificação. Espera-se que permita aos educandos maior acesso à informação e consequente interação.

\section{Justificativa Pedagógica}

É evidente a necessidade de mudanças nos processos de ensino aprendizagem no presente século, visto que, a dita sociedade da informação exige cada vez mais a formação de cidadãos criativos e proativos [Mosé 2013]. Sendo assim, o desenvolvimento de competências e habilidades em relação às novas tecnologias faz-se necessário em todos os níveis de ensino [Perrenoud 2002]. Logo, o Ensino Superior, com destaque para a formação de professores, necessita estar preparada para atender a essas demandas.

Philippe Perrenoud (2002) disserta sobre a necessidade de repensar a formação dos professores deste século, entendendo que os que se formam agora, irão ensinar 
alunos para o futuro. Descreve então um professor que necessita de competências e que usa de estratégias diferenciadas e variadas, centradas nos sujeitos, fazendo com que haja sentido nos saberes. Esse modelo apresenta a elaboração de situações que promovam aprendizagem para que o ensino seja crítico-reflexivo.

Nesse sentido, a diversificação dos processos de ensino e aprendizagem é um caminho para o desenvolvimento de competências em alunos. A Gamificação se mostra como um dos recursos possíveis na formação do pensamento crítico, na construção de saberes através da autonomia e consequente oportunidade de expandir a criatividade e a proatividade [Alves, Minho e Diniz 2014; Aguiar 2010]. De acordo com Kapp (2012) a gamificação consiste no uso de ferramentas, mecânica e dinâmica dos jogos em processos que não necessariamente são pensados para games.

No campo educacional, a gamificação permite que o professor assuma o papel de mediador e o aluno passe de mero receptor para construtor de seus saberes [Figueiredo, Paz e Junqueira, 2015] e nestes as tecnologias inserem-se como recursos potenciais para o processo. Neste sentido, Pretto (2012, p. 99) afirma que a facilidade das tecnologias digitais: "[...] possibilita um olhar profundo para a cultura local e, ao mesmo tempo, um olhar multifacetado e ampliado, conectado com o mundo".

Para que a gamificação se efetive é necessário que ocorra harmonia entre os jogos e os conteúdos propostos [Costa 2008] e que o mesmo seja pensado para o público a quem se destina, sendo avaliadas as características e melhor tipo de abordagem para o grupo [Aguiar 2010].

Dentro da Gamificação, a elaboração de plataformas como recurso ao longo do tempo, pode contribuir para o maior envolvimento e experiência dos alunos. A criação de plataformas que auxiliem a experiência vivida pode fazer com que os educandos possam se envolver, interagir e gerir de forma mais prática e visual suas atividades [Falcão, et al. 2014].

Sendo assim, este trabalho tem como objetivo descrever a construção de um site para o projeto de extensão Colmeia, como um elemento auxiliar no processo de gamificação e consequente engajamento dos alunos à narrativa do jogo, fortalecendo a compreensão sobre os desafios propostos.

\section{Contexto}

O site foi elaborado dentro do Projeto Colmeia, um projeto de extensão que envolve alunos das disciplinas de Didática e Avaliação da Aprendizagem em curso de Licenciatura em Biologia do Centro Acadêmico de Vitória (UFPE). O projeto tem como objetivo desenvolver um processo de gamificação para promoção de competências e habilidades para docência durante a formação inicial na graduação. Ao mesmo tempo propõe experienciação de fundamentos da avaliação da aprendizagem e da didática na prática em escolas públicas do interior de Pernambuco.

O projeto se intitula Colmeia, pois é baseado na sociedade das abelhas, sendo o ambiente da Colmeia a narrativa da gamificação, fazendo com que os educandos possam assumir características das abelhas e trilhar caminhos que envolvam desafios individuais e coletivos para que cada grupo possa planejar uma intervenção em uma escola pública a partir da produção e aplicação de jogos didáticos com os conteúdos da Zoologia, já que o projeto tem ligação interdisciplinar com esta disciplina. 
Ao longo do processo os educandos precisam resolver desafios que envolvem os conteúdos das disciplinas já citadas, ao mesmo tempo em que constroem saberes necessários para uma efetiva intervenção nas escolas. Para que fossem envolvidos na narrativa da gamificação, a pontuação de desafios individuais e coletivos foi denominada de "meles". Ao longo dos desafios os educandos foram acumulando meles individuais e coletivos, os quais ao fim do processo foram convertidos em notas.

Para que pudessem acompanhar sua pontuação ao longo do processo, ter acesso aos desafios e fazer com que ocorresse a imersão na narrativa do jogo, julgou-se pertinente a elaboração de uma plataforma que proporcione aos educandos um acesso dinâmico e envolvente durante o processo da gamificação. A princípio usaram a sala de aula Google (Google Classroom) como espaço de trocas e publicação dos desafios do jogo, porém o modelo padrão desta plataforma não favorece um visual mais conectado entre os desafios, o que nos lançou a decisão de construção de site educacional, objeto deste trabalho.

\section{Processo de Desenvolvimento}

Para criação do site e hospedagem foi utilizada a plataforma unificada do WIX SITE. A plataforma wix permite o usuário criar sites em HTML5 e sites Mobile. Os sites podem vir de uma base pronta ou personalização/criação total. Dentro da plataforma, foram utilizados plugins disponibilizados gratuitamente, quadros em "html", artes vetorizadas, links internos/externos e jogo de camadas secretas (para acesso aos desafios).

Foi criada uma página inicial com informações sobre o projeto, funcionamento do ranking das equipes e uma área de fácil acesso para as duas disciplinas (Figura 1).

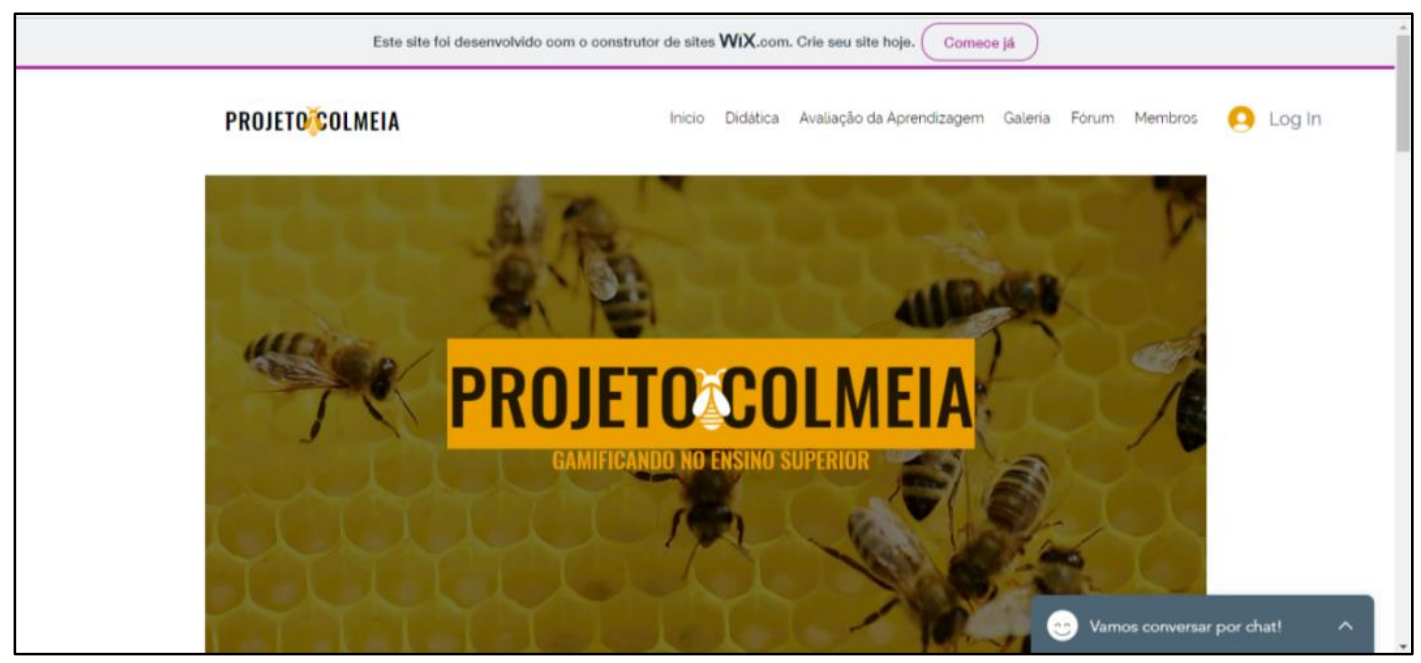

Figura 1: Página inicial do site do Projeto Colmeia

Cada disciplina ganhou uma página onde é possível acompanhar os desafios liberados e o ranking em tempo real. Os botões dos desafios ficam com um símbolo de cadeado e uma mensagem "mouse over" que indica que aquele desafio ainda não foi liberado (Figura 2). 


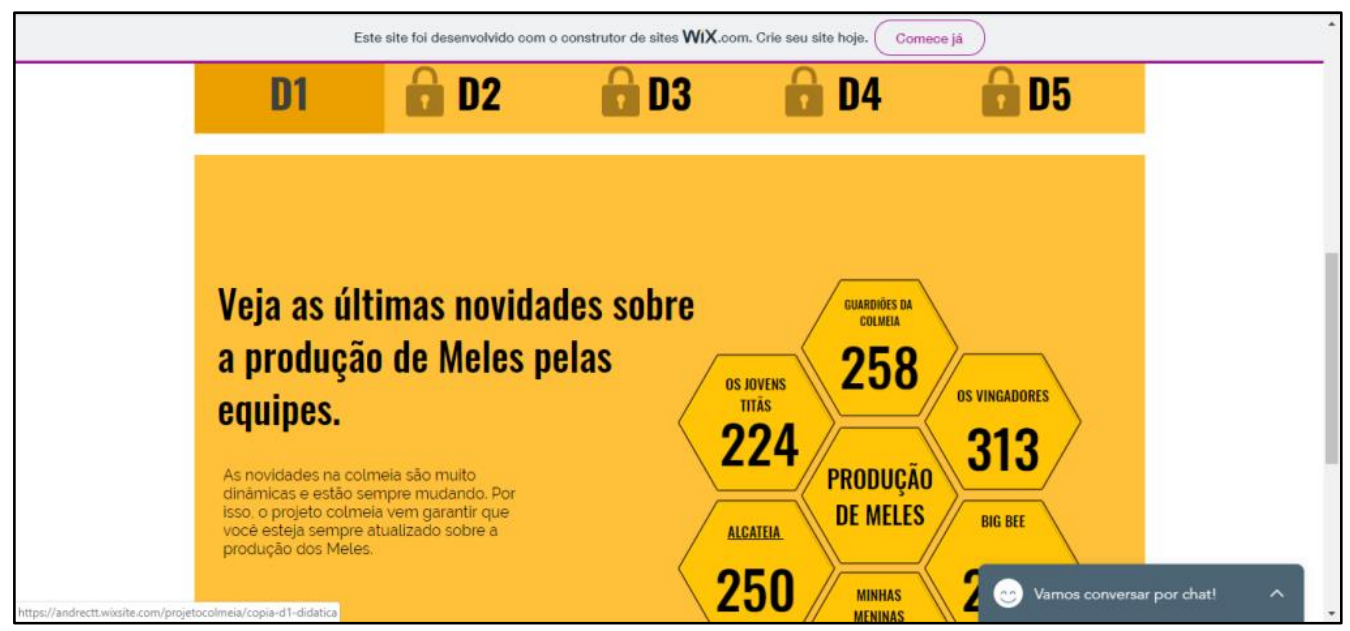

Figura 1: Ranking da disciplina de Avaliação da Aprendizagem e Desafios.

Após liberado, o membro da colmeia é dirigido a uma página de camada invisível que apresenta um infográfico do desafio liberado, com um link direcionado para sala do Google (Figura 3), de forma que pudessem fazer as entregas dos desafios, publicando em um espaço de acesso mais direto para o professor. Ainda há estudos sendo feitos para avaliar a possibilidade destas funcionalidades serem agregadas ao próprio site aqui apresentado.

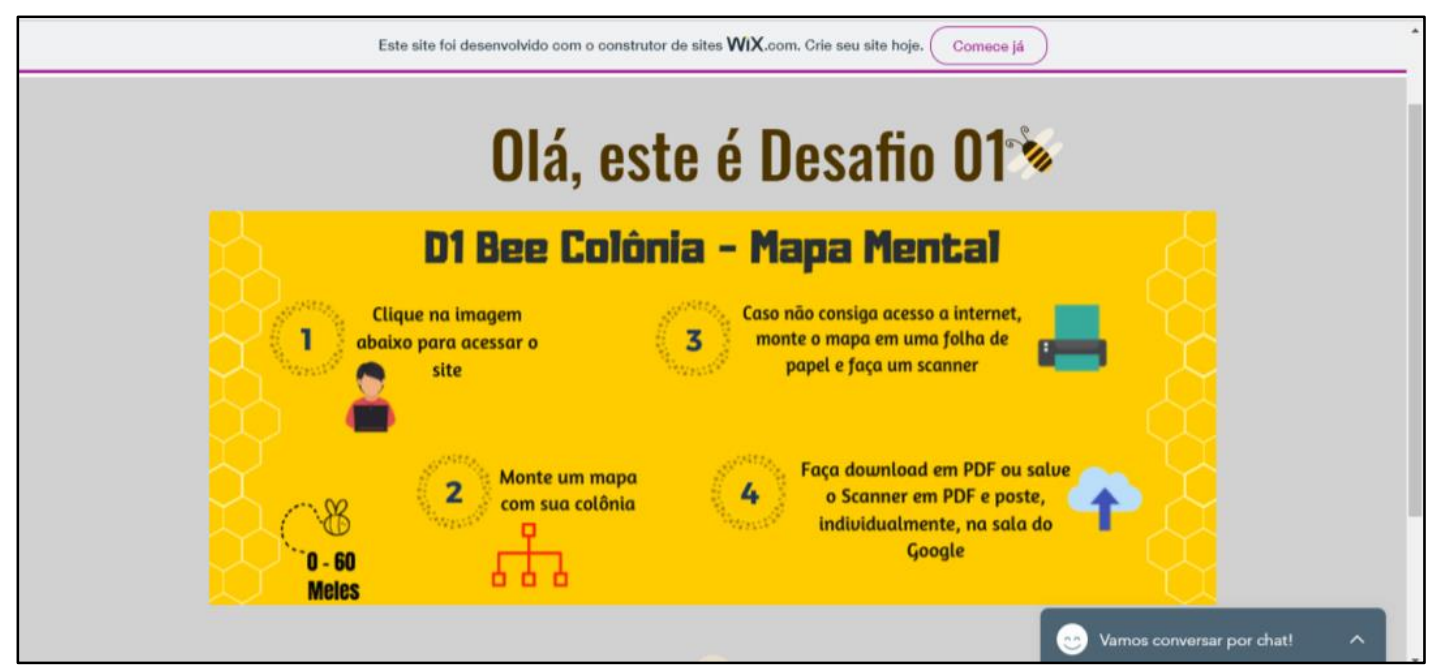

Figura 2: Infográfico mostrando o passo a passo do Desafio que dá acesso à Sala de aula do Google.

Para socialização mais efetiva dos estudantes no processo de gamificação, foi disponibilizado um espaço de fórum no site, o qual permite aos alunos se cadastrarem como membros do projeto e ao fazer login conseguem ver e publicar mensagens de forma unificada entre toda colmeia. Por fim, uma galeria de fotos/vídeos das experiências vividas pela colmeia foi criada e pode ser atualizada periodicamente pelo professor e monitores.

\section{Possíveis Potenciais e Resultados Esperados}

Tendo em vista a perspectiva de Alves (2014), sobre a gamificação, compreende-se que para a promoção de um processo que faça com que alunos interajam 
e tenham prazer no aprender, a iniciativa de construção do site pode proporcionar mais dinamismo, já que nele os estudantes podem interagir através do chat, do fórum, descobrir os próximos desafios do jogo, podendo assim estudar estratégias para melhoria de sua pontuação ao longo do tempo.

Além disso, espera-se que com a construção do site os educandos possam promover a harmonia entre os conteúdos das disciplinas e os jogos, como Costa (2008), coloca que é importante para uma melhor experiência do educando, já que no processo da gamificação a construção de saberes se dá a partir do momento que há o envolvimento com o jogo.

Entendendo o site como uma ferramenta de apoio para a gamificação, espera-se que ele permita aos educandos uma maior jogabilidade, já que a gamificação deve atribuir a característica dos jogos em processos que não necessariamente envolvem jogo, conforme afirma Kapp (2012), mas que deve trazer características de jogo, traduzindo este conceito de forma prática e visual aos participantes.

Além disso, o envolvimento na construção do site possibilitou aos monitores das disciplinas uma experiência diferenciada em termos de monitoria, pois foi possível participar ativamente da construção de um modelo de suporte ao Projeto Colmeia, permitindo que novas competências fossem estimuladas ou mesmo criadas para a nossa formação docente.

O site, ainda não foi aplicado, mas sua estrutura principal já está finalizada e pronta para entrar no ar na continuidade do Projeto no próximo semestre (2019.2). Assim, cria-se aqui uma possibilidade de explorar se as expectativas quanto a esse engajamento dos alunos, irá se concretizar ou não neste processo. Ficando aqui uma fonte de pesquisa futura de continuidade de nosso trabalho.

\section{Referências}

Aguiar, M. P. (2010). Jogos eletrônicos educativos: instrumento de avaliação focadonas fases iniciais do processo de design. Universidade Federal do Paraná, Programade Pós-Graduação em Design.

Alves, L. R. G., Minho, M. R. S. e Diniz, M. V. C. (2014) Gamificação: diálogos com a educação.In: Fadel, L. M. et al. (Org.). "Gamificação na Educaçãa”" (pp. 74-97). SãoPaulo, Pimenta Cultural.

Kapp, K. M. (2012)The Gamification of learning and instruction: Game-based methodsand strategies for training and education. Pfeiffer. Hoboken, NJ.

Costa, L. D. (2008) O que os jogos de entretenimento têm que os jogos com finspedagógicos não têm: princípios para projetos de jogos com fins pedagógicos.Dissertação de Mestrado, Rio de Janeiro.

Falcão, A. P. et. al. (2014) Ferramenta de apoio ao ensino presencial utilizando gamificação e design de jogos. In: Anais do XXV SBIE. Dourados - MS.

Figueiredo, M., Paz, T., \& Junqueira, E. (2015) Gamificação e educação: um estado da arte das pesquisas realizadas no Brasil. Anais dos Workshops do IV Congresso Brasileiro de Informática na Educação (CBIE), pp. 1154 - 1163.

Mosé, Viviane. (2013) A escola e os desafios contemporâneos. Rio de Janeiro: Civilização Brasileira. 
Perrenoud, P. et al. (2002). As competências para ensinar no século XXI: a formação dos professores e o desafio da avaliação; Porto Alegre: Artmed.

Pretto, N. (2012). Professores-autores em rede. In: Pretto, N., Santana, B. e Rossini, C.(Org.). Recursos educacionais abertos: práticas colaborativas políticas públicas(pp. 91-108). Salvador, UFBA, São Paulo, Casa de Cultura Digital. 